\title{
Weight Rhythms: Weight Increases during Weekends and Decreases during Weekdays
}

\author{
Anna-Leena Orsama ${ }^{a} \quad$ Elina Mattila ${ }^{a} \quad$ Miikka Ermes $^{a} \quad$ Mark van Gils ${ }^{a}$ \\ Brian Wansink $^{\mathrm{b}} \quad$ Ilkka Korhonen $^{\mathrm{c}}$ \\ ${ }^{a}$ VTT Technical Research Centre of Finland, Tampere, Finland, ${ }^{b}$ Charles S. Dyson School of \\ Applied Economics and Management, Cornell University, Ithaca, NY, USA, 'Department of \\ Biomedical Engineering, Tampere University of Technology, Tampere, Finland
}

\section{Key Words}

Weight gain · Weekly weight rhythm · Patterns of weight fluctuation · Compensation

\begin{abstract}
Background/Aims: The week's cycle influences sleep, exercise, and eating habits. An accurate description of weekly weight rhythms has not been reported yet - especially across people who lose weight versus those who maintain or gain weight. Methods: The daily weight in 80 adults (BMI 20.0-33.5 kg/m²; age, 25-62 years) was recorded and analysed to determine if a group-level weekly weight fluctuation exists. This was a retrospective study of 4,657 measurements during 15-330 monitoring days. Semi-parametric regression was used to model the rhythm. Results: A pattern of daily weight changes was found $(p<0.05)$, with higher weight early in the week (Sunday and Monday) and decreasing weight during the week. Increases begin on Saturday and decreases begin on Tuesday. This compensation pattern was strongest for those who lost or maintained weight and weakest for those who slowly gained weight. Conclusion: Weight variations between weekends and weekdays should be considered as normal instead of signs of weight gain. Those who compensate the most are most likely to either lose or maintain weight over time. Long-term habits may make more of a difference than short-term splurges. People prone to weight gain could be counselled about the importance of weekday compensation.

(c) 2014 S. Karger GmbH, Freiburg
\end{abstract}


Orsama et al.: Weight Rhythms: Weight Increases during Weekends and Decreases during Weekdays

\section{Introduction}

Obesity is a powerful, prevalent predictor of poor health. In 2010, 475 million adults were obese (BMI $\geq 30 \mathrm{~kg} / \mathrm{m}^{2}$ ) [1] and the number is estimated to grow to $1,115.8$ million by 2030 [2]. Harmful health consequences are manifold: Obesity increases the risk of type II diabetes and cardiovascular diseases [3], osteoarthritis [4], gallstones [4], colon and breast cancer [5], and the incidence of mental disorders [6]. While it is driven by excess intake of energy and inactivity $[7,8]$, a better understanding of weight gain patterns could provide useful insights into the prevention and treatment of obesity.

Human behaviour and physiology exhibit variations according to biological and environmental factors. For instance, circadian rhythms that are seen in the recurrence of our daily activity and rest are also found in the fluctuations of several physiological variables such as body temperature, blood pressure [9], and glucose metabolism [10]. Menstrual cycles are an example of biological monthly rhythms. Recent studies have highlighted the importance of certain rhythms on health. These have included how disruptions in the circadian rhythm influence the development of type II diabetes [11] along with other adverse health consequences [12].

The 7-day cycle of a week also has a strong impact on life [13] that is more environmental and behavioural than biological. For instance, days of the week are known to determine our sleeping patterns [14], physical activity $[15,16]$, and eating habits $[16,17]$. There is early indication that weight is higher during weekends and lower during weekdays [18-20]. However, it is unclear if this phenomenon is visible on a population level and how it is related to successful weight management in the long term.

This research examines the variation of weight across the days of the week and also examines this pattern across three segments of people - those who maintain their weight, gain weight, and lose weight. Specifically, by combining self-monitored weight measurements from four earlier studies, we endeavoured i) to find out whether there is group level variation in weight within a week or whether the weight variation is independent from days of the week; ii) to study the form of the dependence between weight and days of the week; and iii) to initially explore how this might vary across weight losers, weight gainers, and weight maintainers.

\section{Material and Methods}

\section{Retrospectively Collected Weight Data}

Self-recorded weight measurements were aggregated from four earlier data collection efforts [18, 20-22] in which individuals were instructed to self-monitor and record their daily weight, immediately after waking up and before breakfast. Studies 1, 3, and 4 involved health management intervention and were approved by local ethics committees. The focus of Study 2 was usability and feasibility of a mobile phone application and, thus, no approval was needed. Table 1 describes the goals and durations of the four studies as well as the demographics and size of the study populations.

In total, the four studies involved 178 subjects and resulted in 7,408 self-recorded weight measurements (from 154 individuals). Two inclusion criteria regarding the frequency of weight measurements and the length of the monitoring period were established for the data. Only measurements taken on a minimum of 7 sequential days were included to prevent describing a biased rhythm that could result from unreported measurements. The minimum acceptable duration of monitoring was 14 days. These restrictions resulted in the inclusion of 80 adults and 4,657 weight measurements. The length of each individual's time series varied from 15 to 330 days. 
Orsama et al.: Weight Rhythms: Weight Increases during Weekends and Decreases during Weekdays

Table 1. Summary (mean, standard deviation, range or frequency (percentile)) of aggregated weight data in this retrospective set-up

\begin{tabular}{|c|c|c|c|c|}
\hline & Study I & Study II & Study III & Study IV \\
\hline Goal & $\begin{array}{l}\text { descriptive study } \\
\text { on long-term health } \\
\text { variations in healthy } \\
\text { volunteers }\end{array}$ & $\begin{array}{l}\text { feasibility and } \\
\text { usability study of a } \\
\text { mobile application } \\
\text { for weight } \\
\text { management }\end{array}$ & $\begin{array}{l}\text { occupational } \\
\text { health intervention } \\
\text { programme }\end{array}$ & $\begin{array}{l}\text { occupational health } \\
\text { promotion } \\
\text { programme }\end{array}$ \\
\hline Study population & $\begin{array}{l}\text { working-age } \\
\text { adults }\end{array}$ & $\begin{array}{l}\text { working-age, } \\
\text { overweight } \\
\text { adults }\end{array}$ & $\begin{array}{l}\text { working-age } \\
\text { adults with stress } \\
\text { problems }\end{array}$ & $\begin{array}{l}\text { working-age adults } \\
\text { with multiple health } \\
\text { risks }\end{array}$ \\
\hline $\begin{array}{l}\text { Number of } \\
\text { individuals, } \mathrm{n}\end{array}$ & 14 & 29 & 17 & 118 \\
\hline Duration, weeks & $7-11$ & 12 & 12 & 52 \\
\hline Sex male/female & $14 / 0$ & $20 / 9$ & $3 / 14$ & $35 / 83$ \\
\hline Age, years & $42.0,3.0,36-46$ & $39.0,8.1,25-54$ & $54.5,5.4,40-62$ & $45.0,7.1,30-55$ \\
\hline BMI, $\mathrm{kg} / \mathrm{m}^{2}$ & $25.0,3.1,21.0-31.0$ & $28.8,2.4,24.8-33.6$ & $26.8,3.3,22.3-33.3$ & $27.5,4.5,19.6-41.0$ \\
\hline
\end{tabular}

\section{Derivation of Variables}

Based on the original data set, the individuals were divided into three subgroups according to their relative weight change. Relative weight changes were calculated as a difference between the averages of selfmeasured weights on the first and last week of monitoring. The categories of the corresponding group variable were the following: 'LOSS' - weight change more than -3\%; 'GAIN' - weight change more than 1\%; 'MAINTAIN' - weight change between -3 and $1 \%$.

A weight trend component was estimated by applying a two-sided moving average filter [23] with the length of 7 days. Detrended weight measurements were normalised with respect to each individual by mean centring according to one's average weight. The response variable was derived by subtracting trend from weight time series of each individual to eliminate the effects of linear weight gain or linear weight loss. A rapidly decreasing trend may cause weight to appear higher in the beginning of each week-long period which could confound the underlying 'real' rhythm. For the day of the week variable, days were labelled in an ordinal scale as follows: 1 = Sunday, $2=$ Monday, $3=$ Tuesday, $4=$ Wednesday, $5=$ Thursday, $6=$ Friday, $7=$ Saturday.

\section{Statistical Methods}

Semi-parametric regression [24] was used for analysing the weekly rhythm in the weight measurement data. The method is based on the combination of non-parametric smoothing and parametric linear mixedeffects (LME) models [25]. LME models are widely used in the analysis of longitudinal data due to their ability to account for within-subject variation. Splines are continuous piecewise-defined linear functions that are formed by dividing the range of the covariate into $p$ subintervals and modelling each of the intervals with an appropriate slope [26]. The subintervals are tied together at their cut points to make the final curve contiguous. Splines are unrestricted to parametric assumptions and, thus, enable flexible shapes for the curves. As a semi-parametric method, the splines were formulated as LME models and further estimated in the LME framework using the restricted maximum likelihood method (REML).

Student's t-test and restricted maximum likelihood ratio test (RLRT) were used for model comparisons. The RLRT is constructed by comparing maximized likelihoods of two models. The larger the difference between the likelihoods, the stronger the evidence that the smaller model is inadequate. Significance tests were conducted with the risk level $\alpha=0.05$. Analyses were done using R version 2.15 [27]. 
Orsama et al.: Weight Rhythms: Weight Increases during Weekends and Decreases during Weekdays

\section{Application}

The general formula for modelling the dependence between weight and day of the week was the following:

$$
\text { weight }=f(\text { day of the week })+\varepsilon
$$

First, $\mathrm{f}$ (day of the week) was determined as a linear function of day of the week and later extended to a linear penalised spline. The formula of the spline model was:

weight $=\beta_{0}+\beta_{1} \times$ day of the week $+\sum_{r=1}^{6} b_{r}$ (day of the week $\left.-\tau_{\mathrm{r}}\right)_{+}$

On the right hand side, the first two terms form the linear basis for the spline (the formula is similar to the ordinary linear regression model). $\mathrm{b}_{\mathrm{r}+1}$ 's are the slope estimates for the truncated line functions that handle the departures from the linearity to obtain the appropriate form for the curve. In our models, days of the week were used as placements for the cut points ( $\tau$ 's) leading to six subintervals to be modelled with a different slope.

The LME model presentation, $\mathrm{y}=\mathrm{X} \beta+\mathrm{Zb}$ [25], for the spline curve was obtained by partitioning the spline model components in formula (2) into two LME model components, i.e. fixed effects (X $\beta$ ) and random effects (Zb). One of the LME model assumptions holds that slope estimates of the random part are distributed with zero mean [25]. This property is exploited in the estimation to control the roughness of the curve. The advantage of the LME presentation is that it is straightforward to extend the spline model further to account for the within-subject variation that is present in repeated measures data. The random effect structure was extended to individual-specific intercepts and slopes by extending the $\mathrm{Zb}$ component and its corresponding covariance matrix [28]. As a first step, an individual-specific intercept was added to the group-level model where component $\mathrm{u}_{\mathrm{i} 1}$ is an intercept for $\mathrm{i}$-th individual:

$$
\mathrm{f}(\text { day of the week })=\beta_{0}+\beta_{1} \times \text { day of the week }+\sum_{r=1}^{6} b_{r}\left(\text { day of the week }-\tau_{r}\right)_{+}
$$

Further, the model was enlarged with individual-specific linear lines with the day of the week as a covariate. As a final step, the model was extended with individual-specific splines, meaning that each individual had their own spline curve that describes the deviation from the group-level curve. The deviation curve was not restricted to being linear; it could be of any shape. This model was expressed as

$$
\text { weight }=f(\text { day of the week })+g_{i} \text { (day of the week) }
$$

where $g_{i}^{\prime} s$ were constructed as presented in formula (2) but with fewer cut points, i.e. four in our models.

\section{Hypotheses}

Figure 1 shows the initial illustration of the weekly profile curves derived as an averaged detrended normalized weight on each day of the week. Based on the figure, three hypothesis set-ups were formulated. These resulted in the construction of six different models. Primarily, we modelled the group-level data that included the entire sample of 80 subjects. These models were denoted as $\mathrm{M} 1_{\mathrm{ALL}}$ to $\mathrm{M} 6_{\mathrm{ALL}}$. Additionally, each hypothesis set-up was tested in the subgroups of weight losers, weight gainers, and weight maintainers. The models were denoted as $\mathrm{M} 1_{\text {Loss }}$ to $\mathrm{M} 6_{\mathrm{LOSS}}, \mathrm{M} 1_{\mathrm{GAIN}}$ to $\mathrm{M} 6_{\mathrm{GAIN}}$, and M1 $1_{\text {MAINTAIN }}$ to M6 $6_{\text {MAINTAIN }}$.

Day of the Week Effect

The first hypothesis involved testing whether the day of the week had a linear effect on weight when starting from Sunday, or whether the expected weight is constant and does not depend on the day of the week. The following hypothesis was tested:

$\mathrm{H}_{0}:$ weight $=\beta_{0}\left(\mathrm{M} 1_{\mathrm{ALL}}, \mathrm{M} 1_{\text {LOSS }}, \mathrm{M} 1_{\mathrm{GAIN}}, \mathrm{M} 1_{\text {MAINTAIN }}\right)$

$\mathrm{H}_{\mathrm{a}}$ : weight $=\beta_{0}+\beta_{1} \times$ day of the week (M2 $\left.2_{\mathrm{ALL}}, \mathrm{M} 2_{\mathrm{LOSS}}, \mathrm{M} 2_{\text {GAIN }}, \mathrm{M} 2_{\text {MAINTAIN }}\right)$.

To assess the superiority of $\mathrm{M} 2$, the significance of $\beta_{1}$ was tested using the t-statistic. 
Orsama et al.: Weight Rhythms: Weight Increases during Weekends and Decreases during Weekdays

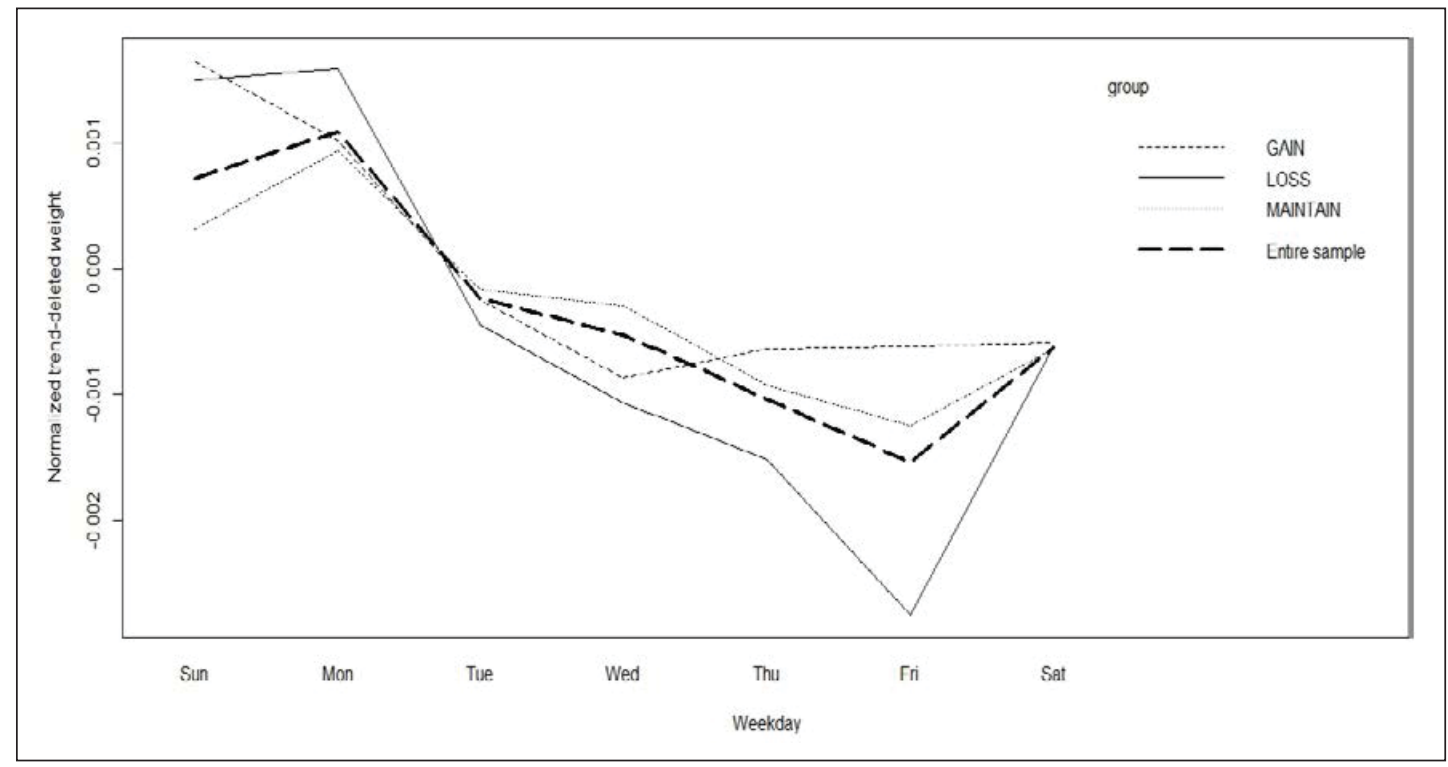

Fig. 1. The initial weekly rhythm profile curves derived as an average weight of each day of the week.

\section{Form of the Dependence}

The second question consisted of two parts, $2 \mathrm{~A}$ and $2 \mathrm{~B}$. In $2 \mathrm{~A}$, the form of the dependence between weight and day of the week was explored. It was tested whether the linear curve was adequate to describe the weekly rhythm or, alternatively, whether there was some degree of nonlinearity. M2 models were tested against their extensions, i.e. linear penalised spline models (M3) that correct departures from the linearity. The following hypothesis was tested:

$\mathrm{H}_{0}$ : weight $=\beta_{0}+\beta_{1} \times$ day of the week (M2 $\left.2_{\mathrm{ALL}}, \mathrm{M} 2_{\mathrm{LOSS}}, \mathrm{M} 2_{\mathrm{GAIN}}, \mathrm{M} 2_{\text {MAINTAIN }}\right)$

$\mathrm{H}_{\mathrm{a}}$ weight $=$
$\beta_{0}+\beta_{1} \times$ day of the week $+\sum_{r=1}^{6} b_{r}$ (day of the week $\left.-\tau_{\mathrm{r}}\right), \mathrm{b}_{\mathrm{r}} \sim \mathrm{N}\left(0, \sigma_{\mathrm{b}}{ }^{2}\right)\left(\mathrm{M} 3_{\mathrm{ALL}}, \mathrm{M} 3_{\mathrm{LOSS}}, \mathrm{M} 3_{\mathrm{GAIN}}, \mathrm{M} 3_{\text {MAINTAIN }}\right)$.

RLRT was used to assess the significance of the difference between the M2 and M3 models. The comparison involved testing if all the six truncated line coefficients $b_{r}$ 's in M3 differed from zero. This is equivalent to testing if $\sigma_{\mathrm{b}}{ }^{2}$ is significantly different from zero. Thus, the hypothesis was simplified as the following:

$\mathrm{H}_{0}: \sigma_{\mathrm{b}}^{2}=0$ versus $\mathrm{H}_{\mathrm{a}}: \sigma_{\mathrm{b}}^{2}>0$.

The testing problem is non-standard because weight measurements are not independent and because the RLRT statistic under the null hypothesis is zero, which is on the boundary of its parameter space [29]. To overcome this problem, we used RLRsim library [30] in R that exploits parametric bootstrap with 10,000 repetitions to simulate and test the hypothesis.

\section{Effect of Longitudinal Nature of the Data}

In order to take the longitudinal nature of the data into consideration, the dependence in measurements made by the same individual was accounted for in $2 \mathrm{~B}$. The fitted population level curves were extended with individual-specific intercepts and slopes. The following models nested to their random effect structures were fitted:

$\left(\mathrm{M} 4_{\mathrm{ALL}}, \mathrm{M} 4_{\mathrm{LOSS}}, \mathrm{M} 4_{\mathrm{GAIN}}, \mathrm{M} 4_{\text {MAINTAIN }}\right):$

weight $=\beta_{0}+\beta_{1} \times$ day of the week $+\sum_{r=1}^{6} b_{r}$ (day of the week $\left.-\tau_{\mathrm{r}}\right)_{+}+\mathrm{u}_{\mathrm{i} 1}$

$\left(\mathrm{M}_{\mathrm{ALL}}, \mathrm{M} 5_{\mathrm{LOSS}}, \mathrm{M} 5_{\mathrm{GAIN}}, \mathrm{M} 5_{\text {MAINTAIN }}\right):$

weight $=\beta_{0}+\beta_{1} \times$ day of the week $+\sum_{r=1}^{6} b_{r}$ (day of the week $\left.-\tau_{r}\right)_{+}+u_{i 1}+u_{i 2} \times$ day of the week 
Orsama et al.: Weight Rhythms: Weight Increases during Weekends and Decreases during Weekdays

Table 2. Data description and baseline characteristics (mean, standard deviation, range or mean (standard deviation)) for entire sample and for subgroups

\begin{tabular}{|c|c|c|c|c|c|c|}
\hline & \multicolumn{3}{|c|}{ Entire sample } & \multicolumn{3}{|l|}{ Subgroups } \\
\hline & all & women & men & LOSS & GAIN & MAINTAIN \\
\hline \multicolumn{7}{|l|}{ Sex } \\
\hline Female & 40 & & & 11 & 4 & 25 \\
\hline Male & 40 & & & 7 & 6 & 27 \\
\hline Age, years ${ }^{\mathrm{a}}$ & $\begin{array}{l}45.3,8.5 \\
25-62^{\mathrm{a}}\end{array}$ & $\begin{array}{l}47.8,8.0 \\
25-58^{\mathrm{a}}\end{array}$ & $\begin{array}{l}\text { 42.6, 8.1, } \\
26-62\end{array}$ & $\begin{array}{l}46.2,11.1 \\
25-62\end{array}$ & $\begin{array}{l}42.6,7.7 \\
29-54^{\mathrm{a}}\end{array}$ & $\begin{array}{l}45.4,7.6 \\
26-58\end{array}$ \\
\hline BMI, kg/m² & $\begin{array}{l}26.9,3.5 \\
20.0-33.5^{b}\end{array}$ & $\begin{array}{l}25.7,3.2 \\
20.8-33.5^{b}\end{array}$ & $\begin{array}{l}27.9,3.4 \\
20.0-32.9\end{array}$ & $\begin{array}{l}26.9,3.1 \\
20.4-31.0\end{array}$ & $\begin{array}{l}26.9,2.9 \\
24.0-32.6^{\mathrm{a}}\end{array}$ & $\begin{array}{l}26.8,3.8 \\
20.0-33.5^{\mathrm{a}}\end{array}$ \\
\hline $\begin{array}{l}\text { Original number of } \\
\text { measurements per } \\
\text { individual }\end{array}$ & $80(58)$ & $85(65)$ & $75(52)$ & $92(69)$ & $59(20)$ & $80(59)$ \\
\hline $\begin{array}{l}\text { Included number of } \\
\text { measurements per } \\
\text { individual }\end{array}$ & $58(56)$ & $55(63)$ & $62(48)$ & $60(62)$ & $48(28)$ & $60(58)$ \\
\hline $\begin{array}{l}\text { Total number of } \\
\text { analysed measurements }\end{array}$ & 4,657 & & & 1,071 & 471 & 3,115 \\
\hline
\end{tabular}

M6:
weight $=\beta_{0}+\beta_{1} \times$ day of the week $+\sum_{r=1}^{6} b_{r}$ (day of the week $\left.-\tau_{r}\right)_{+}+u_{i 1}+u_{i 2} \times$

day of the week $+\sum_{r=1}^{4} \nu_{r}$ (day of the week $\left.-\delta_{\mathrm{r}}\right)_{+}$

The hypothesis concerning the models was whether the added random component improves the fit. The comparison was done by RLRT. The significance of the difference between the two models was tested using Self-Liang approximation [31] which says that asymptotical RLRT follows $1 / 2 \chi_{q}^{2}+1 / 2 \chi_{q+1}^{2}$ - distribution where $\mathrm{q}$ is the number of fixed effects. However, the distribution holds under the assumption that $\mathrm{y}^{\prime}$ are independent which is not the case in the longitudinal data. Therefore, the results were confirmed by comparing the most adequate model with the population average model by using RLRsim library. The observed RLRT's were compared to the 95th percentile of $1 / 2 \chi^{2}{ }_{0}+1 / 2 \chi^{2}{ }_{1}$ - distribution, which is 1.921 .

\section{Results}

The descriptive data of the entire sample and each of the subgroups, i.e. weight losers, weight gainers, and weight maintainers, are shown in table 2 along with the number of measurements obtained from individuals. Table 3 presents how often the minimum and maximum weight observations occurred on different days of the week. In the LOSS group, there was a clear difference between days of the week that have the highest proportions for minimum and maximum weight. The minimum weight of the week was most frequently observed on Friday and, in $60 \%$ of the cases, the week's minimum weight occurred either on Friday or Saturday. Correspondingly, the maximum weight was reached most often on Sunday or Monday, i.e. in 59\% of the cases. In the GAIN and MAINTAIN groups there was more variability. Both the minimum and maximum weight of the week was most frequently measured on Sunday in both subgroups. The second highest occurrence in maximum weight was seen on Monday. The distribution on other days of the week was similar. 
Orsama et al.: Weight Rhythms: Weight Increases during Weekends and Decreases during Weekdays

Table 3. Percentages of each day of the week used to obtain minimum and maximum weight measures

\begin{tabular}{|c|c|c|c|c|c|c|}
\hline \multirow{2}{*}{$\begin{array}{l}\text { Day of the } \\
\text { week }\end{array}$} & \multicolumn{2}{|l|}{ LOSS } & \multicolumn{2}{|c|}{ GAIN } & \multicolumn{2}{|c|}{ MAINTAIN } \\
\hline & $\min , \%$ & $\max , \%$ & $\min$, & $\max , \%$ & $\min$ & $\max , \%$ \\
\hline Sunday & 6 & 40 & 25 & 25 & 26 & 30 \\
\hline Monday & 4 & 19 & 13 & 19 & 11 & 21 \\
\hline Tuesday & 7 & 9 & 6 & 10 & 12 & 13 \\
\hline Wednesday & 9 & 5 & 19 & 4 & 11 & 9 \\
\hline Thursday & 14 & 7 & 13 & 14 & 11 & 10 \\
\hline Friday & 39 & 6 & 10 & 11 & 15 & 8 \\
\hline Saturday & 21 & 14 & 14 & 17 & 13 & 8 \\
\hline
\end{tabular}

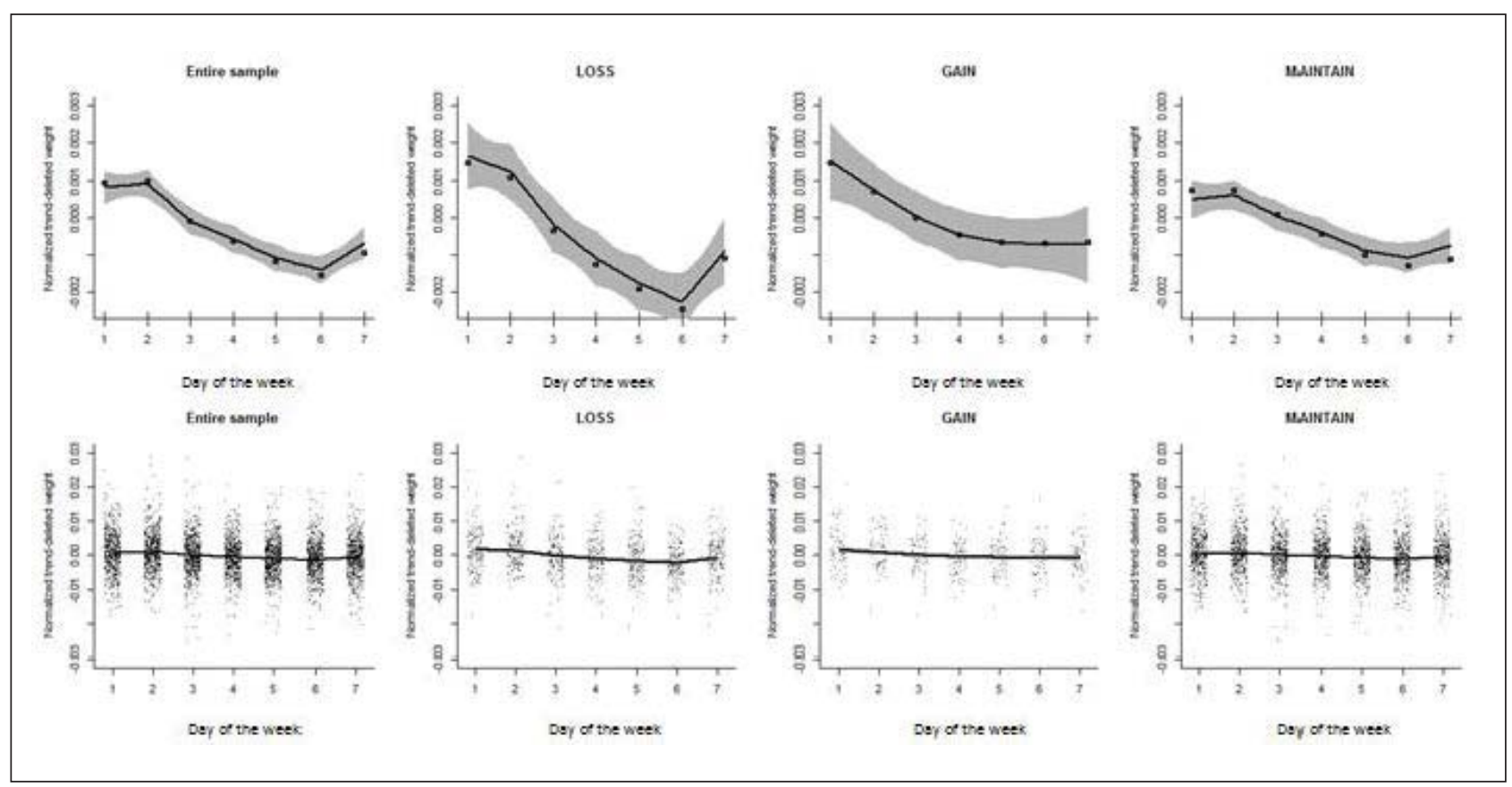

Fig. 2. Fitted profile curves of the weekly weight rhythms and their variability bands.

When examining the day of the week effect with a linear regression model, day of the week was a significant predictor of weight in all study groups $(p<0.001$ for the entire sample, for LOSS, and for MAINTAIN; $p=0.002$ for GAIN). The slopes that describe the rate of weight change were all negative: $\beta_{1}=-0.0004$ for the entire sample, $\beta_{1}=-0.0006$ for LOSS, $\beta_{1}=$ -0.0003 for GAIN, and $\beta_{1}=-0.0003$ for MAINTAIN.

The linear association of day of the week on weight was not adequate to explain the weekly variation of weight but it was significantly better explained by a spline curve that allowed a more flexible shape ( $p<0.001$ for the entire sample, $p<0.001$ for LOSS, $p=0.021$ for MAINTAIN, $\mathrm{p}=0.065$ for GAIN). Therefore, the spline model was used to test the $2 \mathrm{~B}$ hypothesis.

The weekly rhythm-fitted plots with their variability bands are shown in figure 2 . The upper panel shows fitted profile plots of the weekly rhythm of weight with their variability bands. Equivalent plots are fitted in the lower panel together with scatter plots of weight 
Orsama et al.: Weight Rhythms: Weight Increases during Weekends and Decreases during Weekdays

Table 4. Test statistics of the restricted maximum likelihood ratio test to assess the superiority of different models that differ in their random-effect structure

\begin{tabular}{lllll}
\hline & Entire sample & LOSS & GAIN & MAINTAIN \\
\hline M4 versus M3 & 71.93 & 63.23 & $<0.001$ & 27.45 \\
M5 versus M4 & 57.19 & 10.85 & 4.37 & 38.02 \\
M6 versus M5 & 6.03 & $<0.001$ & $<0.001$ & $<0.001$ \\
\hline
\end{tabular}

M3: weight $=\beta_{0}+\beta_{1} \times$ day of the week $+\sum_{r=1}^{6} b_{r}\left(\text { day of the week }-\tau_{r}\right)_{+}$

M4: weight $=\beta_{0}+\beta_{1} \times$ day of the week $+\sum_{r=1}^{6} b_{r}$ (day of the week $\left.-\tau_{r}\right)_{+}+u_{i}$

M5: weight $=\beta_{0}+\beta_{1} \times$ day of the week $+\sum_{r=1}^{6} b_{r}\left(\text { day of the week }-\tau_{r}\right)_{+}+$

$u_{i 1}+u_{i 2} \times$ day of the week

M6: weight $=\beta_{0}+\beta_{1} \times$ day of the week $+\sum_{r=1}^{6} b_{r}$ (day of the week $\left.-\tau_{r}\right)_{+}+$

$u_{i 1}+u_{i 2} \times$ day of the week $+\sum_{r=1}^{4} v_{r}$ (day of week $\left.-\delta_{r}\right)_{+}$

measurements of each group to illustrate the explorative role of rhythm curves in the weight variation.

Table 4 shows the test statistics of RLRT to assess the most adequate fit that takes into account the within-subject variation in the data. The model that included subject-specific lines (M5) was the most adequate model in the LOSS, GAIN, and MAINTAIN subgroups. In all cases, the likelihood ratio statistic for assessing M5 over M4 was greater than 1.921. Further extension of the random effect structure to the individual-specific splines made no improvement. The superiority of M5 over M3 models (that did not account for individual effects) was confirmed by simulations using RLRsim. The bootstrapped $p$-values were: $p=0$ for LOSS, $\mathrm{p}=0.056$ for GAIN, and $\mathrm{p}=0$ for MAINTAIN. For the entire sample, the most adequate model was the M6 that included individual-specific splines. The bootstrapped p-value of comparing the superiority $\mathrm{M}_{\mathrm{ALL}}$ against $\mathrm{M} 3_{\mathrm{ALL}}$ was 0 . The addition of individual-specific trajectories to population level models significantly decreased the unexplained variability in this weight data. However, the extensions did not change the shape of curves but they remained similar to the population level curves. The fitted values of the models are plotted as separate points in figure 2 . We see hardly any difference from the population level curves that are drawn as contiguous lines.

\section{Discussion}

The purpose of this study was to explore the weekly rhythm of weight to understand the normal variation of weight which occurs during the week. In addition, we described the rhythm profiles in different weight management groups. It was found that the day of the week has a significant effect on weight: weight was higher in the beginning of the week, i.e. on Sunday and Monday, and decreased toward the end of the week. In addition, there was a slight increase in the end of the week, i.e. during Saturdays and Sundays. This phenomenon was also observed in the subgroups of weight losers and weight maintainers, but not among weight gainers. This observation may appear contradictory but is explained by the fact that we removed any linear weight change prior to analysing the effect of day of the week - therefore, it is possible for the GAIN group to exhibit this pattern.

The detected shape of the weekly rhythm of weight is consistent with the results of other studies regarding day of the week effects on human behaviour. Meal sizes and calorie intake have been found to increase $[16,17]$ and physical activity to decrease during weekends [15], 
specifically on Sundays [16]. The increased calorie intake and reduced amount of exercise are indicators that are associated with weight gain. Correspondingly, we detected weight gain during weekends. The shape of the weekly rhythm curves were consistent with the findings of Racette et al. [16] who found a decreasing trend during weekdays but increased weight during weekends. Our analysis reveals that the decreasing trend is continued until Friday after which weight starts to increase over the weekend, being highest on Sunday and on Monday.

Based on the subgroup analyses, our results suggest that weekly variation of weight might be associated with weight management. Figure 2 shows that the magnitude of the weekly weight variation is greater in the LOSS group than in the GAIN group. This suggests that individuals in the GAIN group have less consistent weight differences between days of the week and that their weight varies with less regularity. This is also noticeable in table 3: In the LOSS group, the minimum weight of the week is most often observed at the end of the week while the week's maximum weight is most often seen either on Sunday or Monday. In the GAIN group, maximum and minimum weights of the week are distributed more evenly to all days of the week. Similar findings can be seen in the research of Racette et al. [16]. In both of their intervention groups, significant decreases in weight $(-8.0 \pm 0.9 \mathrm{~kg}$ and $-6.4 \pm 0.9 \mathrm{~kg})$ were detected whereas in the control group the average weight change was $-1.3 \pm 0.9 \mathrm{~kg}$. Correspondingly, both of the intervention groups had decreasing weight during weekdays and stable or increasing weight during weekends whereas the control group did not show significant weight changes on weekends or weekdays.

Based on the subgroup analysis, it appears that successful weight control (weight maintenance or weight loss) is not distracted by slight increases in weight during weekends. Instead, their success seems to be related to their ability to compensate and turn down the upward trend. This compensation mechanism thwarts minor weight regains, which Phelan et al. [32] found difficult for many people to recover from. However, relapses are expected and likely to occur in weight management. Successful weight loss strategies have indicated that flexible dietary restraint involves less pressure on diet and a stronger understanding of how diet and energy balance relate to sustained weight loss [33].

Flexible eating regulation patterns that allow one to enjoy all foods and compensate for more caloric meals are more likely to be sustained in a long-term rather than a dichotomous way of thinking ('all or nothing' or 'allowed/forbidden foods') [33]. Similarly, Dohm et al. [34] reported that when dietary lapses occur, successful weight maintainers are more likely to use direct coping. Allowing more flexibility on weekends and holidays might be more realistic from a long-term perspective because it avoids dietary boredom [35]. Indeed, according to a study by Smith et al. [36], the most common reasons for stopping a weight loss regimen were 'boredom/loss of interest' and 'missing certain foods'. Therefore, contrary to the conclusions of Racette and co-authors [16], slight variations - including increases in weight during the weekend - may have a positive role in supporting long-term successful weight management.

One limitation of this study pertains to the threshold value of the GAIN group (1\% of weight increase). Whether $1 \%$ is an actual increase or merely a part of daily weight variation may be discussed. However, to eliminate day-to-day fluctuations in weight, the individuals were classified according to weight change that was calculated as an average of weight selfmeasurements over one week. Secondly, as self-monitoring relates to weight loss and successful loss maintenance [37-39], individuals showing early signs of weight gain despite regular self-monitoring were classified in the GAIN group of this study to emphasize their deviation from the expected pattern. Despite this low threshold, our sample size of the GAIN group was small, which limits the generalizability of the results and highlights the overall challenge of learning more about weight gainers. It is difficult to find people who are committed to consistently monitoring their weight with frequency and continuity even in the presence 
Orsama et al.: Weight Rhythms: Weight Increases during Weekends and Decreases during Weekdays

of unfavourable outcomes. The threshold value for the LOSS group was set to a decrease of weight of $>3 \%$. For obese people (BMI $>30 \mathrm{~kg} / \mathrm{m}^{2}$ ), a moderate weight reduction of $5 \%$ is generally considered to be beneficial for health [40]. In this study, individuals were on average overweight (mean BMI $27.3 \mathrm{~kg} / \mathrm{m}^{2}$ ) but not obese and the monitoring time was relatively short, i.e. 80 days on average. Therefore, we expected smaller weight loss and considered a decrease of 3\% sufficient. This threshold is also supported by Stevens et al. [41].

A challenge that we faced in the analysis was the depletion of data. The unbalance of the data and the self-selected nature of weight measurements make the data sensitive to bias. To achieve generalizable results, certain requirements were established for the measurement frequency and consistency to avoid the slightest fluctuations of weight. As a result, the number of weight measurements decreased from 7,408 to 4,657. Due to the small sizes of GAIN and LOSS groups (10 and 18 individuals, respectively), the suggested relationship between the weekly rhythm and weight management success should be considered preliminary.

The findings of this study suggest that weight should not be expected to be constant throughout the week. Slight increases during weekends can be treated as normal weight variation instead of signs of weight gain. However, the slight weight gain over weekends needs to be compensated during weekdays to avoid an increasing long-term trend. Based on the indicators of this study, a clear weekly rhythm may be favourable, allowing for more flexible eating patterns. However, more research is needed to confirm these results across a broader range of ages and life circumstances. The results were inherited from a retrospective set-up, and none of the studies was primarily planned for the analysis of weekly variation of weight. Future studies require careful consideration to obtain a sufficient amount of data regarding weight gainers while at the same time retaining the free-living set-up to obtain generalizable results.

\section{Conclusion}

This study found that there is a clear weekly rhythm to weight variation. Weight was at the highest point after weekends, on Sunday and Monday, and decreased toward the end of the week. The beginning of the weekend stopped the decrease and weight started to increase after Friday. Additionally, there is preliminary evidence that those people who show the largest compensating change from the weekend to the weekdays are those who-over time - are most likely to either lose weight or maintain their weight. It appears that long-term habits make more of a difference than short-term splurges.

Based on the findings of this study, we can expect weight to rise during weekends and treat it as a normal variation. Our results provide scientific support to the tenet that in weight management, allowing more flexibility during weekends and holidays might be more realistic and successful in the long term than a strict regimen.

\section{Acknowledgments}

AO, EM, ME, MV, BW, and IK conceived and designed the study. AO, EM, ME, MV, and IK collected and analysed data. AO, BW, and IK wrote the manuscript. Julia Hastings-Black provided editorial assistance.

\section{Disclosure Statement}

This work was done as a part of the ITEA2 Care4me project. The project is funded by the Finnish Funding Agency for Technology and Innovation (Tekes) and the VTT Technical Research Centre of Finland (VTT).

The authors have no conflicts of interest to disclose. 
Orsama et al.: Weight Rhythms: Weight Increases during Weekends and Decreases during Weekdays

\section{References}

1 International Association for the Study of Obesity (IASO): Obesity the Global Epidemic. 2011. www.iaso.org/ iotf/obesity/obesitytheglobalepidemic/. Accessed July 2012.

2 Kelly T, Wang W, Chen C-S, Reynolds K, He J: Global burden of obesity in 2005 and projections to 2030. Int J Obes (Lond) 2008;32:1431-1437.

-3 Doll HA, Petersen SE, Stewart-Brown SL: Obesity and physical and emotional well-being: associations between body mass index, chronic illness, and the physical and mental components of the SF-36 questionnaire. Obes Res 2000;8:160-170.

4 Mokdad AH, Ford ES, Bowman BA, Dietz WH, Vinicor F, Bales VA, Marks JS: Prevalence of obesity, diabetes and obesity-related health risk factors, 2001. JAMA 2001;289:76-79.

5 Calle EE, Thun MJ: Obesity and Cancer. Ongocene 2004;23:6365-6378.

6 Gatineau M, Dent M: Obesity and Mental Health. Oxford, National Obesity Observatory, 2011.

7 Hill J, Wyatt H, Reed G, Peters J: Obesity and environment: where do we go from here? Obesity 2003;299: 853-855.

8 Friedman J: A war on obesity, not the obese. Obesity 2003;299:856-858.

$>9$ Turjanmaa V, Kalli S, Majahalme S, Saranummi N, Uusitalo A: Diurnal blood pressure profiles and variability in normotensive ambulant participants. Clin Physiol 1987;7:389-401.

10 Rutter J, Reick M, McKnight S: Metabolism and the control of circadian rhythms. Annu Rev Biochem 2002;71: 307-331.

11 Gale J, Cox H, Qian J, Block G, Colwell C, Matveyenko A: Disruption of circadian rhythms accelerates development of diabetes through pancreatic beta-cell loss and dysfunction. J Biol Rhythms 2011;26:423-433.

12 Van Someren E, Riemersma-Van Der Lek RF: Live to the rhythm, slave to the rhythm. Sleep Med Rev 2007;11: 465-484.

13 Zerubavel E: The Seven Day Circle: The History and the Meaning of the Week. Chicago, University of Chicago Press, 1989.

14 Monk RH, Buysse DJ, Rose LR, Hall JA, Kupfer DJ: The sleep of healthy people - a diary study. Chronobiol Int 2000; 7:49-60.

15 Buchowski MS, Acra S, Majchrzak KM, Sun M, Chen KY: Patterns of physical activity in free-living adults in the Southern United States. Eur J Clin Nutr 2004;58:828-837.

16 Racette S, Weiss E, Schechtman K, Steger-May K, Villareal DT, Obert KA, Holloszy JO: Influence of weekend lifestyle on body weight. Obesity (Silver Spring) 2008;16:1826-1830.

17 De Castro JM: Weekly rhythms of spontaneous nutrient intake and meal pattern of humans. Physiol Behav 1991;50:729-738.

18 Tuomisto MT, Terho I, Korhonen I, Lappalainen R, Tuomisto T, Laippala P, Turjanmaa V: Diurnal and weekly rhythms of health-related variables in home recordings for two months. Physiol Behav 2006:87;650-658.

19 Lappalainen R, Pulkkinen P, van Gils M, Pärkkä J, Korhonen I: Long-term self-monitoring of weight: a case study. Cogn Behav Ther 2005;34:108-114.

20 Mattila E, Lappalainen R, Pärkkä J, Salminen J, Korhonen I: Use of mobile phone diary for observing weight management and related behaviours. J Telemed Telecare 2010;16:260-264.

-21 Mattila E, Pärkkä J, Hermersdorf M, Kaasinen J, Vainio J, Samposalo K, Merilahti J, Kolari J, Kulju M, Lappalainen $\mathrm{R}$, Korhonen I: Mobile diary for wellness managements - results on usage and usability in two user studies. IEEE Trans Inf Technol Biomed 2008;12:501-512.

22 Hopsu L, Simonen R, Halonen J, Konttinen J, Mattila E, Lindholm H, Leino T: Health promotion in occupational health care setting: effects of an intensive health promotion: Nuadu study. Barents Newsl Occup Health Saf 2010;13:56-59.

23 Brockwell P, Davis R: Introduction to Time Series and Forecasting. New York, Springer, 1996.

24 Ruppert D, Wand MP, Carroll RJ: Semiparametric Regression. Cambridge, UK, Cambridge University Press, 2003.

25 Pinheiro JC, Bates DM: Mixed-Effects Models in S and S-PLUS. New York, Springer, 2000.

26 Eilers PH, Marx BP: Flexible smoothing with B-splines and penalties. Statist Sci 1996:11;89-121.

27 R Development Core Team: R: A Language and Environment for Statistical Computing. Vienna, 2011. www.Rproject.org/.

28 Durban M, Harezlak J, Wand M, Carroll R: Simple fitting of individual-specific curves for longitudinal data. Stat Med 2005;24:1153-1167.

29 Crainiceanu CM, Ruppert D: Restricted likelihood ratio tests in nonparametric longitudinal models. Stat Sin 2004:14;713-729.

30 Scheipl F, Bolker B: RLRsim: Exact (Restricted) Likelihood Ratio tests for mixed and additive models. 2012. http://cran.r-project.org.

-31 Self SG, Liang K: Asymptotic properties of maximum likelihood estimators and likelihood ratio test under nonstandard conditions. J Am Statist Assoc 1987;82:605-610.

32 Phelan S, Hill J, Lang W, Dibello J, Wing R: Recovery from relapse among successful weight maintainers. Am J Clin Nutr 2003;78:1079-1084.

-33 Texeira P, Silva M, Coutinho S, Aplmeira A, Mata J, Vieira O, Carraca E, Santon T, Sardinha L: Mediators of weight loss and weight loss maintenance in middle-aged women. Obesity (Silver Spring) 2010;18:725-735. 
Dohm FA, Beattie JA, Albel C, Striegel-Moore RH: Factors differentiating women and men who successfully maintain weight loss from women and men who do not. J Clin Psychol 2001;57:105-107.

-35 Gorin A, Phelan S, Wing R, Hill JO: Promoting long-term weight control: does dieting consistency matter. Int J Obes 2004;28:278-281.

-36 Smith CF, Burke LE, Wing RR: Vegetarian and weight-loss diets among young. Obes Res 2000;8:123-129.

- 37 Phelan S, Liu T, Gorin A, Lowe M, Hogan J, Fava J, Wing R: What distinguishes weight-loss maintainers from treatment-seeking obese? Analysis of environmental, behavioural and psychosocial variables in diverse populations. Ann Behav Med 2009:38;94-104.

-38 Kruger J, Blanck HM, Gillespie C: Dietary and physical activity behaviours among successful at weight loss maintenance. Int J Behav Nutr Phys Act 2006:3:17.

-39 Butryn ML, Phelan S, Hill JO, Wing RR: Consistent self-monitoring of weight: a key component of successful weight loss maintenance. Obesity (Silver Spring) 2007;15:3091-3096.

40 Pasanisi F, Contaldo F, de Simone G, Mancini M: Benefits of sustained moderate weight loss in obesity. Nutr Metab Cardiovasc Dis 2001;11:401-406.

41 Stevens J, Truesdale KP, McClain JE, Cai J: The definition of weight maintenance. Int J Obes (Lond) 2006;30: 391-399. 